\title{
Drug Accountability Assessment Reason Not Done
}

National Cancer Institute

\section{Source}

National Cancer Institute. Drug Accountability Assessment Reason Not Done. NCI

Thesaurus. Code C87867.

The explanation given as to why drug accountability was not assessed. 